\title{
Proposta de análise integrada de emergências em saúde pública por arboviroses: o caso do Zika vírus no Brasil
}

\author{
Proposal for integrated analysis of public health emergencies \\ involving arboviruses: the case of the Zika virus in Brazil
}

\author{
Vera Lucia Edais Pepe', Mariana Vercesi de Albuquerque', Claudia Garcia Serpa Osorio-de- \\ Castro' ${ }^{\mathbf{1}}$ Claudia Cristina de Aguiar Pereira' ${ }^{\mathbf{1}}$, Catia Verônica dos Santos Oliveira' $\mathbf{1}^{\mathbf{1}}$ Lenice Gnocchi

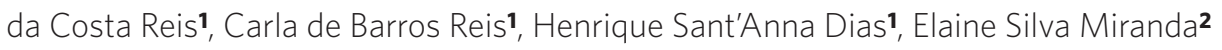

DOI: 10.1590/0103-11042020E205

\begin{abstract}
RESUMO A mudança no padrão de ocorrência da microcefalia associada à infecção pelo Zika Vírus em gestantes no Brasil resultou na decretação de emergência em saúde pública de importância nacional e internacional. Esforços coordenados e multisetoriais foram demandados, mas nem sempre houve respostas efetivas ou preparação das populações afetadas. A epidemia de Zika repercutiu nas políticas públicas, incluindo a de saúde, seja na investigação científica, seja na proposição de medidas de controle, diagnóstico, prevenção e tratamento. Objetivou-se apresentar proposta de análise integrada para abordagem de futuras emergências sanitárias com foco nas arboviroses. Partindo da experiência brasileira da epidemia e literatura relacionada, articularam-se quatro dimensões: vulnerabilidades e risco; condições e impactos socioeconômicos na população; desenvolvimento e emprego de tecnologias e pesquisas; e resposta e reprogramação do sistema de saúde. Pretende-se viabilizar loci específicos de investigação, para mensuração de possíveis desfechos e geração de novas evidências sobre os efeitos da epidemia nos sistemas de saúde. O conhecimento científico e suas lacunas são considerados os principais elementos integradores dessas dimensões analíticas, de forma a contribuir com resposta mais oportuna e efetiva em futuras emergências. Além do conhecimento adquirido, faz-se necessário agregar capacidade de enfrentar futuras emergências relacionadas com as epidemias de arboviroses.
\end{abstract}

PALAVRAS-CHAVE Zika vírus. Infecções por arbovírus. Vulnerabilidade a desastres. Emergências em desastres. Sistemas de saúde.

1 Fundação Oswaldo Cruz (Fiocruz), Escola Nacional de Saúde Pública Sergio Arouca (Ensp) - Rio de Janeiro (RJ), Brasil. verapepe@ensp.fiocruz.br

2 Universidade Federal Fluminense (UFF), Faculdade de Farmácia Niterói (RJ), Brasil.

\begin{abstract}
The change in the pattern of occurrence of microcephaly associated with Zika virus infection in pregnant women in Brazil resulted in the declaration of a Public Health Emergency of National and International Concern. Coordinated and inter-sector efforts were required, but there were not always effective responses or preparation of the affected populations. The Zika epidemic impacted public policies, including health policy, both in scientific research, proposals for control measures, diagnosis, prevention, and treatment. The study aimed to propose an integrated analysis for the approach to future health emergencies, with a focus on arboviral infections. Based on the Brazilian experience with the Zika epidemic and the related literature, the analysis links four dimensions: vulnerabilities and risk; the population's socioeconomic conditions and impacts; development and use of technologies and research; and the health system's response and reprogramming. The aim is to allow specific research focuses to measure the possible outcomes and generate new evidence on the epidemic's effect on health systems. Scientific knowledge and its gaps are the main integrating elements in these analytic dimensions, aimed at contributing with a more timely and effective response in future emergencies. Besides the acquired knowledge, it is necessary to add capacity to confront future emergencies related to arbovirus epidemics.
\end{abstract}

KEYWORDS Zika virus. Arbovirus infections. Disaster vulnerability. Disaster emergencies. Health systems. 


\section{Introdução}

Arboviroses são infecções virais com parte do ciclo reprodutivo e transmissão relacionados com insetos hematófagos, que vêm adquirindo importância crescente diante do desordenado crescimento e ocupação das cidades, da globalização e das mudanças climáticas. A resposta a epidemias de arboviroses se constituem desafio para a saúde pública por inúmeros motivos, entre eles: a pletora de agentes etiológicos com diferentes manifestações clínicas, por vezes graves; a dificuldade no controle de vetores; a inexistência de vacina e tratamento efetivos e o acometimento de populações que já se encontram em situação de vulnerabilidade ${ }^{\mathbf{1 , 2}}$.

Em 2015, a detecção da mudança no padrão de ocorrência da microcefalia em recém-nascidos, associada à infecção pelo vírus da Zika em gestantes, intensificou as preocupações com seu caráter epidêmico. Esse contexto impulsionou a decretação de emergência sanitária pelo Brasil, em novembro daquele ano ${ }^{\mathbf{3 , 4}}$, seguida da declaração de Emergência Sanitária de Importância Internacional (ESPII), pela Organização Mundial da Saúde (OMS), em fevereiro de $2016^{5-7}$. Ao longo dos últimos quatro anos, gerou-se grande número de evidências sobre a epidemia, o vírus e os seus efeitos, no que concerne a detecção, formas e controle da transmissão, bem como identificação e tratamento das diferentes manifestações da Síndrome Congênita do Zika Vírus (SCZV), incluindo lesões oculares, auditivas, motoras e alterações cognitivas, presentes mesmo nos casos sem microcefalia.

Tanto as Emergências de Saúde Pública (ESP) como os desastres, sejam de origem natural ou antropogênica, são causados por evento 'iniciador' e avassalador. Dependendo das características das populações, dos lugares e da capacidade de resposta e enfrentamento, esses eventos podem causar danos consideráveis. Além das perdas materiais e de vidas, há consequências, temporárias ou permanentes, em diversos planos da sociedade, como na economia e na saúde 5 . Em ESP, nem sempre populações e lugares acometidos estão preparados ou têm condições efetivas para seu enfrentamento.

Esses eventos demandam esforços de diferentes atores, de modo conjugado, coordenado e multissetorial, em perspectiva local, regional, nacional e global ${ }^{5}$. Essa compreensão orienta a legislação sanitária brasileira, dada a sua importância no aprimoramento da resposta do sistema de saúde, ante a ESP ocorrida no País, e seus desdobramentos ${ }^{\mathbf{8}}$. As características da epidemia do Zika Vírus (ZIKV), e seus efeitos, repercutem diretamente no desenvolvimento das políticas públicas, incluindo a de saúde, com vistas à investigação e à proposição de medidas de diagnóstico e controle, bem como de prevenção e tratamento de suas consequências.

Além do conhecimento adquirido no contexto da epidemia, faz-se necessário avançar nas temáticas que agreguem capacidade de enfrentamento de futuras emergências. É central institucionalizar aprendizados que possibilitem melhor resposta, enfatizando condições de vulnerabilidade e risco; desigualdade e iniquidade no cuidado; direitos sociais das famílias e dos indivíduos afetados; formas de atuação governamental nas emergências e desafios da ação intersetorial.

Tendo por base a literatura, em especial aquela produzida sobre a epidemia do ZIKV no Brasil, objetiva-se apresentar uma proposta de análise integrada das emergências sanitárias relacionadas com as arboviroses, que considera e articula quatro dimensões. A primeira diz respeito à preparação, considerando vulnerabilidades e riscos, na perspectiva da ocorrência de desastres. A segunda considera condições socioeconômicas, especialmente pobreza, como importante condicionante da existência e dos efeitos da epidemia. A terceira aborda pesquisas e inovação/utilização de tecnologias, importante integração entre a saúde e demais setores sociais envolvidos no desenvolvimento científico e tecnológico. A quarta e última dimensão diz respeito à resposta e reprogramação do sistema de saúde, 
considerando sua capacidade institucional no manejo das emergências sanitárias, com destaque ao desenvolvimento e interação das políticas públicas; e à análise, atuação e reorganização do sistema e serviços de saúde para o enfrentamento da epidemia.

Pressupõe-se que, diante de futuras emergências sanitárias, o sistema de saúde possa construir e implementar uma resposta mais oportuna e efetiva, a partir desses elementos e das experiências e aprendizados com eventos anteriores.

\section{Caracterização de vulnerabilidades e risco}

Em geral, populações mais pobres são de maior risco para desastres e emergências em saúde ${ }^{9}, o$ que ficou denotado na epidemia de Zika. Grupos populacionais específicos, como mulheres e crianças, estão entre os mais vulneráveis e precisam atenção especial e priorização do cuidado $^{10}$. A vulnerabilidade - neste caso específico, a vulnerabilidade social desses grupos - nasce diretamente da estrutura social e das suas consequências, como desigualdades de renda, moradia e saneamento, acesso ao sistema de saúde e a cuidados em saúde, e diferenças de empoderamento social. Essas diferenças geram, afinal, exposição desigual a riscos"1".

O início da epidemia deu-se no Nordeste, região brasileira que tem populações vivendo em condições precárias de moradia e saneamento. Ela concentrou o maior número de casos de microcefalia ${ }^{12}$ e vivenciou, em período próximo à epidemia do ZIKV (2013-2015), outras emergências sanitárias, como sífilis ${ }^{13}$ e sarampo, este com ênfase nos estados de Pernambuco e Ceará ${ }^{14}$. Ainda, outras arboviroses como dengue e chikungunya grassavam no Nordeste na mesma época15.

Não foi completamente esclarecida a relação desses acontecimentos e seus fatores determinantes e contributivos, assim como não foram suficientemente evidenciados, até o momento, os impactos para a epidemia do ZIKV. Entretanto, aponta-se que, possivelmente, a população mais vulnerável era a mesma. Além disso, o papel de fatores como cobertura vacinal e proteção cruzada com outras arboviroses segue em investigação. Há dúvidas sobre o possível retorno da epidemia, seja em sua magnitude ou forma ${ }^{\mathbf{1 6}}$.

Os episódios da epidemia, em outros países, não expressaram a magnitude e a gravidade do caso brasileiro. $\mathrm{O}$ conhecimento escasso sobre a doença pela sociedade, pela comunidade científica e por setores envolvidos na prestação de cuidados de saúde e no suporte social dificultou uma resposta tempestiva. Os profissionais de saúde, que fazem a ligação entre esse conhecimento em 'repositório' e a população, por meio de cuidados em saúde, também se viram em situações contraditórias. Não houve preparação, pois, o risco específico, relacionado com as consequências do ZIKV, era, até então, basicamente desconhecido. Os determinantes de vulnerabilidade social, além de controvérsias sobre agente causal e microcefalia, comprometeram a comunicação de risco impoluta e direta para sua mitigação ${ }^{17}$.

No início da epidemia, dados importantes que pudessem melhor denotar e caracterizar o evento e seus riscos não estavam completamente disponíveis. Exemplo disso são os dados da microcefalia no Brasil, com bases pouco expressivas naquele momento. $\mathrm{O}$ aumento de mais de dez vezes de casos registrados, no auge da epidemia, possivelmente se deveu também a outras causas ${ }^{17}$, o que pode ser verificado pelo surge de notificações, muitas delas não relacionadas com a Zika. A epidemia dessa doença mostrou que, na efervescência dos acontecimentos, necessidades urgentes e recorrentes dos afetados vieram à tona. A identificação dos vulneráveis bem como a priorização de cuidados e medidas preventivas para essa população, no Brasil, foram insuficientes ${ }^{\mathbf{1 2}}$.

A participação de quaisquer sujeitos em pesquisa deve respeitar sua dignidade e orientar-se pelos propósitos da pesquisa científica. A pesquisa em emergências sanitárias e desastres suscita acalorada discussão ética. A epidemia de Zika ensejou um influxo considerável de 
pesquisas e pesquisadores, de origem nacional e internacional18. A expectativa era de que essas pesquisas fossem sempre pautadas pela melhor conduta na relação com os afetados, uma vez que são os mais suscetíveis a eventuais excessos ou impropriedades na condução das pesquisas; procede, portanto, a preocupação com as pesquisas nas populações mais vulneráveis ao ZIKV ${ }^{19}$.

O setor saúde é especialmente demandado em emergências, e, dessa forma, deve estar preparado para atender à necessidade dos grupos que apresentam maiores vulnerabilidades sociais, físicas, ambientais e econômicas. É dever da comunidade científica aprender e propor medidas e estratégias de redução de risco não apenas para o futuro, mas também para populações presentemente afetadas ${ }^{20}$. A respeito de redução de risco, o que podemos dizer que aprendemos com a epidemia de Zika? São lições aplicáveis somente a essa emergência ou podem ser extrapoladas a outras? A preparação envolve arcabouço de medidas e de políticas que transcendem as possibilidades dos agora afetados. As comunidades atingidas e que permanecem em situações de vulnerabilidade não estão preparadas. Apenas pequeno grupo, de mães e filhos afetados, pode ter possibilidade de reação, por condições de resiliência expressas na capacidade de organização e criação de redes e vínculos solidários.

\section{Condições e impactos socioeconômicos nas famílias de crianças afetadas pela epidemia de Zika}

A epidemia do ZIKV teve profunda relação com condições socioeconômicas dos indivíduos afetados $^{\mathbf{1 8 , 2 1}}$. Se, por um lado, ter baixos níveis de renda e escolaridade tornou os indivíduos mais vulneráveis em um contexto epidêmico, por outro, esses mesmos indivíduos foram afetados desigualmente, com implicações para domicílios, famílias e mercado de trabalho. A infecção pelo vírus pode resultar no nascimento de crianças com SCZV, que traz desfechos irreversíveis e crônicos para sua saúde, com elevada morbidade 22,23 .

Pelo ponto de vista microeconômico, o nascimento de uma criança com SCZV tem relação direta com o risco de empobrecimento, o que pode trazer limitações às possibilidades de consumo, educação, lazer e trabalho, no presente e no futuro, bem como reduzir a qualidade de vida ${ }^{24-27}$. O crescimento das crianças afetadas pela SCZV impõe necessidades de atenção e cuidado dos familiares, principalmente das mães que precisam se dedicar aos cuidados de vida diária e dispor de tempo para levá-las aos serviços de saúde de que necessitam ${ }^{\mathbf{2 8}}$.

No nível domiciliar e familiar, esse choque negativo na saúde traz mudanças na capacidade de obtenção de renda e nos padrões de gastos. Consequências econômicas abarcam custos diretos e indiretos, como custos financeiros, abdicação de horas dedicadas ao mercado de trabalho e tempo gasto no cuidado à criança, os quais forçam a família a buscar estratégias para lidar com a nova situação instalada. Tais estratégias podem ser a substituição do trabalho intra e interdomiciliar, uso de poupança e outros investimentos, venda de ativos, busca de empréstimos, entre outras. Essa dinâmica pode resultar em uma armadilha de pobreza para indivíduos e famílias 24,26,29.

Em todos esses cenários, pode-se esperar elevação do nível de pobreza, com prejuízos para a formação de capital físico, humano e financeiro dos envolvidos. A depender da gravidade da doença, as implicações podem ser de caráter intergeracional, com repercussões para o nível de desenvolvimento socioeconômico futuro dos indivíduos, famílias e comunidades ${ }^{30}$. Por exemplo, ao atingirem idade escolar, haverá necessidade de adaptação do sistema de ensino para acolher e educar as crianças, conforme suas habilidades cognitivas e capacidades de aprendizagem ${ }^{31,32}$. Pode haver, também, menor interesse em prover 
incentivos, no âmbito da educação, tendo em vista o comprometimento da expectativa/ qualidade de vida e, portanto, de aquisição de conhecimentos e habilidades ${ }^{33}$.

A compreensão da dinâmica econômica nos domicílios afetados torna-se importante, principalmente para que se possam aferir as reais dimensões das consequências econômicas da SCZV. Para a estimação dos custos totais incorridos à sociedade, é importante não apenas entender a perspectiva do Sistema Único de Saúde (SUS), mas considerar todos os setores afetados $^{34}$, sendo a perspectiva das famílias uma importante chave para essa percepção mais ampliada.

Tanto os custos médicos quanto não médicos podem ter implicações para a proteção financeira e vulnerabilidade das pessoas afetadas, especialmente no que diz respeito aos desembolsos diretos que podem perpetuar ou levar os indivíduos a situações de pobreza e a um ciclo contínuo de doença e pobreza ${ }^{29}$, principalmente por se tratar de uma doença crônica ${ }^{25}$. A despeito da importância desses custos para o bem-estar de indivíduos e famílias, há pouca evidência empírica, no nível dos domicílios, sobre a carga das doenças crônicas, a qual é vital para a elaboração de políticas públicas ${ }^{\mathbf{2 4}}$. Por exemplo, custos com transportes aos serviços de saúde podem representar uma grande parcela dos gastos totais com saúde ${ }^{35,36}$, portanto, devem ser mensurados. Assim também, os custos com alimentação e hospedagem relacionados com a busca pelo cuidado de saúde devem ser considerados ${ }^{29}$.

As famílias também podem incorrer em custos indiretos, que são aqueles relacionados com a perda de produtividade no mercado de trabalho, decorrente dos padrões de morbidade e mortalidade prematura associados ao evento. A SCZV pode afetar atividades da vida diária de mães, pais e outros familiares das crianças afetadas, impondo diminuição na qualidade e na quantidade de horas de trabalho e lazer.

Considerando uma perspectiva temporal dos impactos da epidemia de Zika, algumas evidências sugerem a geração de carga econômica de volume considerável tanto em curto quanto em longo prazo. Um estudo de avaliação de impacto realizado pelo Programa das Nações Unidas para o Desenvolvimento, ao analisar os dados para alguns países da América Latina e Caribe, estimou que os custos totais do Zika na região são similares aos custos envolvidos na epidemia de dengue ${ }^{37}$. A queda das receitas com turismo internacional e doméstico e os dispêndios diretos com diagnóstico e tratamento representaram os principais responsáveis pelos custos de curto prazo, ou seja, custos computados dentro do período de duração da epidemia. Entre 2015 e 2017, a estimativa de ônus variava de US\$ 7 bilhões a US\$ 18 bilhões na região. Apesar dos países mais pobres terem sido os mais afetados - considerando os custos como proporção do Produto Interno Bruto (PIB) -, o Brasil suportou a maior carga absoluta dos custos de curto prazo graças a maior incidência dos casos associados às condições congênitas. Já os custos de longo prazo - que consideram todos os custos incorridos entre o início da epidemia até o tempo estimado de expectativa de vida da coorte de indivíduos afetados pela epidemia - são majoritariamente representados pelos custos diretos e indiretos associados à microcefalia e à Síndrome de Guillain-Barré. Para os cuidadores de crianças afetadas pela SCZV, principalmente mulheres adolescentes e jovens, a perda de produtividade por deixarem o mercado de trabalho e abandono dos estudos fortalece o ciclo de pobreza em que estão inseridas. Para as crianças afetadas, os custos envolvem, além de perda de produtividade ao longo de toda a vida, as necessidades específicas quanto aos cuidados de saúde, na atenção doméstica, educação e transporte. Os distúrbios neurocognitivos já manifestados desde o nascimento devem permanecer por toda a vida resultando em atrasos no desenvolvimento neuropsicomotor, por meio de problemas de equilíbrio e coordenação, convulsões, irritabilidade, dificuldades na deglutição e na fala, além de problemas visuais e auditivos ${ }^{38}$. Os custos totais de longo prazo previstos para 
essas condições podem atingir as cifras de US\$ 29 bilhões e US $\$ 10$ bilhões respectivamente ${ }^{37}$. Esses números sustentam o grande impacto econômico da epidemia para a sociedade.

\section{Desenvolvimento e emprego de tecnologias e pesquisas}

A epidemia do ZIKV também teve reflexos no desenvolvimento científico e tecnológico, tendo em vista a necessidade do avanço de conhecimento, do desenvolvimento e uso de tecnologias, sejam as que representam a organização do conhecimento já existente sobre as arboviroses, sejam as que foram necessárias para preencher algumas lacunas. Foram estabelecidas parcerias com instituições internacionais, facilitadas pela declaração da ESPII, que exigiu ação coordenada para pesquisa e desenvolvimento de novas tecnologias para seu enfrentamento ${ }^{39}$.

No plano governamental, a epidemia orientou a definição de editais de pesquisa científico-tecnológica, envolvendo Ministérios e órgãos de fomento brasileiros, direcionados para, entre outros, imunologia e virologia, novas tecnologias diagnósticas e de promoção/ prevenção; estratégias de controle vetorial; tecnologias sociais e inovação em educação ambiental e sanitária; inovação em gestão de serviços de saúde, de saneamento e de políticas públicas e epidemiologia e vigilância em saúde ${ }^{40}$. A pesquisa e o desenvolvimento de novas tecnologias têm-se concentrado tanto em tecnologias diagnósticas, terapêuticas e de prevenção como nas de controle de vetores.

Tecnologias diagnósticas abrangem diagnóstico da doença e identificação de complicações da SCZV. O desafio tem sido obter testes capazes de diagnosticar arboviroses específicas, permitindo identificar os casos de cada uma delas e os indivíduos acometidos por mais de uma delas, informações fundamentais para elucidar a magnitude de cada uma das arboviroses, estimar sua transcendência e entender os efeitos das infecções associadas em um mesmo indivíduo ${ }^{\mathbf{4 1}, \mathbf{4 2}}$. Acesso às tecnologias para diagnóstico das complicações do ZIKV persiste como um desafio, uma vez que, no Brasil, o acesso à média e à alta complexidade ainda é um gargalo do sistema de saúde ${ }^{43}$. Diagnóstico ou tratamentos tardios e descontinuados, especialmente nos bebês, podem dificultar o alcance do maior desenvolvimento possível ou acarretar retrocesso no quadro de saúde. Garantir acesso aos meios diagnósticos e terapêuticos, já existentes, no momento oportuno, é fundamental para reduzir impactos negativos ${ }^{\mathbf{4 4}}$.

Vacinas e estratégias de controle de vetores são importantes tecnologias de prevenção e controle ${ }^{45,46}$. Há cerca de 40 a 60 instituições no mundo com diferentes estratégias para o desenvolvimento de vacinas: vírus inativados, partículas virus-like e vacinas com vírus recombinantes e DNA ${ }^{45}$. No entanto, até o momento, não há nenhuma disponível no mercado. Pesquisas em animais indicam possibilidade de que a vacina da febre amarela tenha efeito protetivo contra o ZIKV, podendo reduzir a carga do vírus no cérebro e seus efeitos neurológicos ${ }^{47,48}$.

As estratégias de controle de vetores incluem tecnologias conhecidas e utilizadas para dengue, como ações educativas, levantamento rápido do índice de infestação de Aedes aegypti (LIRAa), aplicação de larvicidas e uso de armadilhas para a redução e eliminação da população de mosquitos ${ }^{41}$. Sistemas de informação mais integrados e 'inteligentes', que utilizam tecnologias geoespaciais e modelos computacionais, qualificam o monitoramento e controle da população de Aedes aegypti, bem como compreensão e predição das arboviroses ${ }^{\mathbf{4 9}}$.

Novas tecnologias de controle vetorial incluem manipulação do mosquito, gerando mosquitos transgênicos, estéreis, portadores de Wolbachia e disseminadores do pesticida piriproxifeno. Há também novas armadilhas, como Ovitrampa, para monitoramento dos 
mosquitos ${ }^{\mathbf{4 1}}$. Utilização de repelentes tem feito parte das medidas governamentais de prevenção, e novas formulações estão em desenvolvimento, como uso de nanotecnologia, para diminuição de sua toxicidade ${ }^{50}$. Estudos avaliam eficácia de roupas e mosquiteiros impregnados com repelente na proteção contra picadas de mosquito ${ }^{51}$.

Um dos desafios das tecnologias de cuidados terapêuticos é a descoberta de tratamento específico contra o ZIKV. Alguns estudos, in vitro e in vivo, estão sendo desenvolvidos com o uso de medicamentos e substâncias já aprovadas pelos órgãos reguladores para outras indicações terapêuticas. Por exemplo, sofosbuvir, interferon e outros inibidores da polimerase, eritrosina B e cloroquina ${ }^{52-55}$. Aspecto pitoresco recente é a investigação do ZIKV como tratamento para glioblastoma, tumor cerebral grave e incurável. Isto é, uso do vírus como tecnologia terapêutica ${ }^{\mathbf{4 8}}$.

Em relação às tecnologias de cuidado da SCZV, há um amplo conjunto voltado para reabilitação e prevenção de incapacidades e sequelas apropriadas à necessidade de cada caso, como órteses, próteses e meios auxiliares de locomoção. Novas tecnologias de educação e comunicação em saúde vêm sendo desenvolvidas, como cursos, capacitações, oficinas, cartilhas, folders, vídeos, jogos, aplicativos, páginas eletrônicas, voltadas para profissionais de saúde, famílias e outros atores envolvidos, como professores ${ }^{56}$.

\section{Resposta e reprogramação dos sistemas e serviços de saúde}

O contexto de incertezas e pressões pela produção de evidências sobre Zika impôs desafios aos sistemas e serviços de saúde. Após a apresentação de um plano de resposta da OMS, em 2016, desencadeou-se uma corrida global para estruturação de respostas rápidas de reprogramação com vistas à detecção de casos, ao controle da infecção e tratamento à população afetada ou em risco ${ }^{7,57,58}$.

Na resposta à emergência, é central considerar as pessoas e lugares em risco $^{59}$ e as diferentes concepções e definições dos direitos à saúde em cada país, que apresentam variações quanto à sua garantia e universalidade. Mesmo em países com sistemas universais de saúde, há algum grau de desigualdade e limitação de sua abrangência, influenciando a capacidade de resposta e reprogramação. As configurações político-institucionais dos sistemas de saúde quanto às atribuições, responsabilidades, modelos de atenção, regulação e financiamento também condicionam as respostas às emergências e demandas. Somam-se a isso diferentes tempos entre produção de evidências, estabelecimento de consensos quanto à sua importância social no enfrentamento e decisões públicas para elaboração de respostas.

Outro aspecto importante é o engajamento das instituições nacionais e internacionais de ciência, tecnologia e inovação na formulação e implementação das políticas públicas. Além disso, deve-se considerar o conhecimento tácito pela vivência da epidemia e suas repercussões, para orientar ações governamentais ${ }^{60}$.

No Brasil, epicentro da epidemia, a construção de respostas combinou resgate de caminhos conhecidos e proposição de novas formas de intervenção. Observou-se amplo escopo de iniciativas, incluindo controle vetorial; prevenção de risco; integração dos sistemas de vigilância e atenção; coordenação intergovernamental; articulação intra e intersetorial; ações de comunicação, informação e notificação; qualificação profissional e desenvolvimento de protocolos de diagnóstico e tratamento ${ }^{39}$.

Nos sistemas de controle e vigilância, evidenciou-se a necessidade de aprimoramento da comunicação em momentos de emergência, tanto no sistema de saúde quanto para a população, particularmente a afetada e em risco. Tem-se apontado a relevância dos Sistemas de Informação em Saúde (SIS) na garantia da acessibilidade dos dados, em 
apoio às políticas públicas, devendo-se enfatizar a adoção de estratégias de proteção, monitoramento e segurança dos dados ${ }^{61}$. Por outro lado, a subutilização dos SIS tem-se expressado como barreira para enfrentamento dessa e de outras arboviroses ${ }^{62}$.

As medidas de fortalecimento do planejamento familiar tiveram influência das recomendações internacionais de adiamento da gravidez e ampliação do acesso a métodos contraceptivos, no contexto da epidemia. Faz-se necessário, entretanto, discutir seu limites e efetividade na redução da infecção pelo ZIKV 63-65. Na América Latina e Caribe, por exemplo, apontou-se para baixo uso e disponibilidade do método contraceptivo intrauterino, indicando necessidade de revisão das políticas governamentais, para que assegurem oferta às populações de risco e com maior vulnerabilidade para Zika ${ }^{66}$.

Discussão da ampliação da permissão legal do aborto em qualquer circunstância e a identificação de barreiras de acesso aos métodos contraceptivos decorrentes da política em vigor e seu escopo foram temas evidentes no contexto da ESP67-70. Acrescenta-se que amplo acesso aos serviços e produtos relacionados com a saúde reprodutiva requer informações de qualidade sobre riscos de infecção, suas consequências e tecnologias disponíveis, dando maior capacidade de decisão às mulheres ${ }^{71}$.

No que tange à reorganização dos cuidados de pré-natal, a redução das chances de uma possível contaminação na gestação relaciona-se com avanço no estabelecimento de protocolos que, ao serem aplicados nos serviços de saúde, garantam exames, testagem universal para ZIKV.Em períodos de ESP, advoga-se pela criação de protocolos de compartilhamento dos produtos relacionados com o sangue, com garantia da disponibilidade, bem como a adoção de medidas complementares de segurança dos procedimentos de doação de sangue ${ }^{\mathbf{7 2 , 7 3}}$.

A efetividade do seguimento e rastreamento de problemas de desenvolvimento das crianças no período após o nascimento dependeu da oferta de ultrassom de cabeça, testagem e exame físico abrangente. A estimulação precoce, medida amplamente reconhecida para bebês (até 3 anos) com múltiplas deficiências, embora priorizada, esteve comprometida para boa parte das crianças acometidas por conta da falta de acesso a serviços, equipamentos e tecnologias e de profissionais habilitados e qualificados. A formação e qualificação de profissionais da rede de cuidados se mostrou estratégica para alcançar melhores resultados.

Durante a emergência, evidências científicas, conhecimentos decorrentes de experiências anteriores e produzidos naquele momento foram sendo disseminados por meios de informação e comunicação diversos, públicos e privados. $\mathrm{O}$ engajamento comunitário, de grupos e famílias exerceu papel importante na produção e difusão de conhecimento, contribuindo para pressionar o poder público a dar respostas às necessidades decorrentes da epidemia ${ }^{68}$.

A SCZV tem-se mostrado mais abrangente do que a presença de microcefalia, podendo acometer bebês sem aparente alteração no perímetro cefálico ${ }^{\mathbf{7 4}, 75}$, sendo necessário $\mathrm{o}$ acompanhamento contínuo das crianças dessa geração. A reprogramação deve atentar-se às demandas crescentes de apoio à mulher, à criança e à pessoa com deficiência, tais como: acesso a 'tecnologias assistivas'76; reabilitação intensiva, incluindo órteses e próteses ${ }^{44}$; estimulação precoce com fisioterapeuta, consultas com pediatra, psicóloga e oftalmologista, realização de audiometria e manejo das dificuldades de alimentação ou mobilidade das crianças ${ }^{77}$; acesso aos benefícios de renda e transporte; oferta de cuidadores; acolhimento no sistema educacional78; e apoio psicossocial às pessoas cuidadoras e às famílias ${ }^{79}$.

Ressalta-se que, para as mulheres e crianças atingidas, $o$ acesso aos serviços e aos conhecimentos é marcado por inúmeras condições de desigualdades, que vão se expressar na resposta e na reprogramação ${ }^{\mathbf{8 0 , 8 1}}$. Os protocolos elaborados nem sempre reconhecem e contextualizam restrições decorrentes de desigualdades socioeconômicas, vulnerabilidades e outras barreiras. 
No Brasil, as respostas se deram no contexto de crise política, social e econômica, indicando o comprometimento do investimento científico e tecnológico e a capacidade de resposta e reprogramação do SUS, assim como o agravo das condições socioeconômicas de lugares e populações em risco. Fez diferença a existência de um sistema universal de saúde de proporções continentais e com experiências e atuação diversificadas, apesar das desigualdades e limitações na oferta, acesso, financiamento e dos seus distintos graus de institucionalização e coordenação política.

\section{Proposta de análise e enfrentamento de futuras emergências sanitárias relacionadas com as arboviroses}

A epidemia do ZIKV reitera a importância e a urgência da resposta dos sistemas de saúde, de forma a fazer frente aos seus efeitos e minimizar riscos. Análise das emergências em saúde não é simples e requer considerar o conhecimento científico existente, bem como as incertezas, de modo a indicar caminhos para resposta efetiva e tempestiva, que valorize a compreensão e a articulação dos contextos, e repercussões da epidemia.
O conhecimento científico e suas lacunas configuram-se, portanto, como elemento central e integrador das dimensões trabalhadas, ressaltando-se o caráter transversal da informação e comunicação nas análises das emergências relacionadas com as arboviroses. Essas dimensões estão inseridas em um dado contexto, tridimensional e dinâmico, que possui relação dialética com as condições da população, dos lugares, da epidemia e suas repercussões. Por isso, a articulação entre dimensões e elementos seria direcionada, no sentido de viabilizar loci específicos de investigação e produzir possíveis desfechos que, ao serem mensurados, possibilitem a geração de novo conhecimento e evidências sobre as repercussões da epidemia e as respostas do sistema e serviços de saúde.

Propõe-se que a análise e o enfrentamento de futuras emergências relacionadas com as epidemias de arboviroses pelos sistemas e serviços de saúde considerem, entre outras, questões orientadoras contidas no roteiro do quadro 1. Tal instrumento integra as dimensões desenvolvidas, na medida em que correlacionam alguns de seus elementos, tendo como foco as populações e os lugares atingidos, vulnerabilizados e em maior risco, procurando fugir de lógicas segmentadas e setoriais de orientação de políticas e programas de saúde.

Quadro 1. Roteiro de perguntas orientadoras para análise e enfrentamento de emergências relacionadas com as epidemias de arboviroses

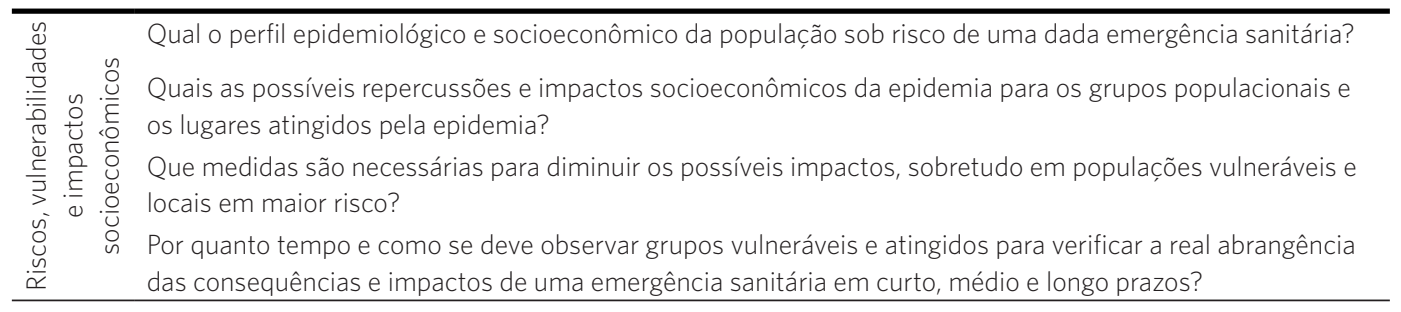


Quadro 1. (cont.)

\begin{tabular}{|c|c|}
\hline \multirow{4}{*}{ 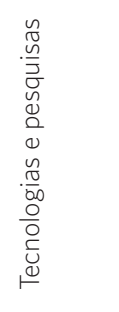 } & $\begin{array}{l}\text { Que experiências prévias, certezas e evidências podem orientar as respos } \\
\text { e quais as incertezas? }\end{array}$ \\
\hline & $\begin{array}{l}\text { Quais tecnologias e conhecimentos, inclusive os produzidos pelas comunidades, podem ser mais bem util } \\
\text { zados, readaptados e/ou difundidos, e quais aqueles que precisam ser produzidos/criados? }\end{array}$ \\
\hline & $\begin{array}{l}\text { Como garantir que as tecnologias e conhecimentos produzidos alcancem popu } \\
\text { atingidos, considerando escalas e desigualdades de acesso e difusão? }\end{array}$ \\
\hline & $\begin{array}{l}\text { Quais pesquisas } \\
\text { em curto, médio }\end{array}$ \\
\hline \multirow{5}{*}{ 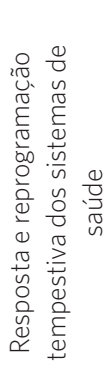 } & 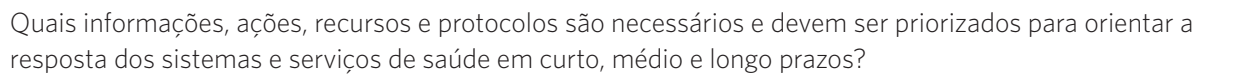 \\
\hline & $\begin{array}{l}\text { Que tipo de capacitação ou alocação de profissionais é necessário para respo } \\
\text { durante a emergência sanitária? }\end{array}$ \\
\hline & $\begin{array}{l}\text { Quais medidas preventivas e de } \\
\text { das das populações vulneráveis e }\end{array}$ \\
\hline & $\begin{array}{l}\text { Quais as possíveis repercussões e impactos da epidemia para os sistemas e serviços de saúde em curto, } \\
\text { médio e longo prazos? }\end{array}$ \\
\hline & Como garantir comunicação ágil e confiável entre gestores, pesquisadores, pessoas atingidas e a população? \\
\hline
\end{tabular}

Fonte: Elaboração própria.

Não foi pretensão constituir um modelo acabado e completo para as ESP por arboviroses. Pelo contrário, a proposta expressa a reflexão e a formulação de algumas questões fundamentais, porém, não exaustivas, para orientar respostas a futuras emergências, que devem ser adaptadas às diferentes realidades. O significado de estar em risco ou estar preparado para o enfrentamento de ESP por arboviroses varia em cada país, lugar e momento. A figura 1 ilustra esquematicamente a proposta analítica integrada.

Figura 1. Proposta da análise integrada de emergências sanitárias relacionadas com as arboviroses
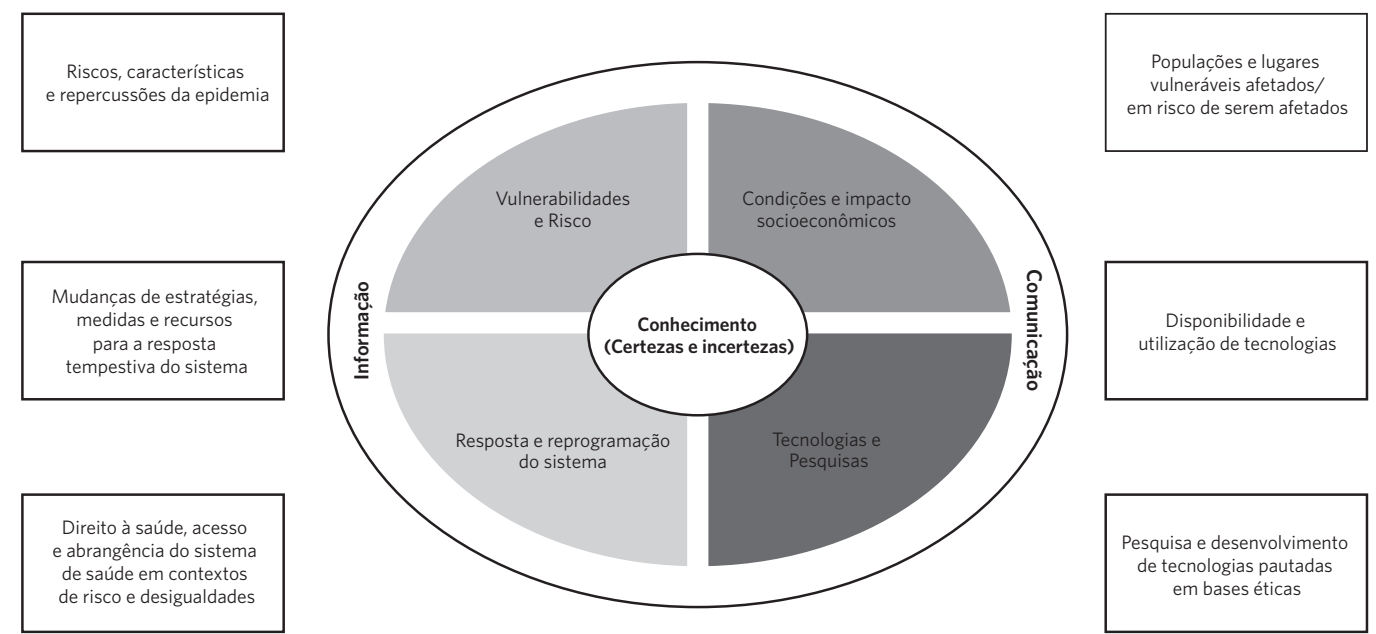

Fonte: Elaboração própria. 
É importante ressaltar que as evidências apontam a necessidade cada vez maior da articulação de políticas, envolvendo todas essas dimensões, dado que elas apresentam alto grau de interdependência. A ativação da cadeia que vai da pesquisa/desenvolvimento aos efeitos da utilização de tecnologias em curto, médio e longo prazos, passando pelas questões de financiamento, acesso e utilização, implica a necessidade de novos mecanismos de coordenação e gestão por parte do Estado. É preciso não apenas executar pesquisas e ações, mas também adquirir capacidade de avaliação dos seus efeitos na população. As políticas e a resposta às emergências devem considerar iniquidades e fatores relacionados com as populações, sobretudo com aquelas em situação de vulnerabilidade e pobreza.

As novas tecnologias diagnósticas ou de tratamento das arboviroses não são efetivas se não houver estratégias governamentais que viabilizem acesso e utilização pela população. Investimentos na produção de evidências científicas que apoiem as políticas de regulação, incorporação e uso de tecnologias são essenciais na resposta a ESP. É fundamental articular estratégias de redução da desigualdade e melhoria das condições de vida, de modo a gerar efeitos protetivos para grupos populacionais mais afetados.

Vacinas, repelentes, medicamentos, tecnologias assistivas precisam estar disponíveis e ao alcance no momento oportuno, além de associadas às ações intersetoriais, especialmente as de proteção social, educação e saneamento básico. A melhoria das condições de vida e socioeconômicas podem reduzir a vulnerabilidade e os riscos associados à situação de pobreza. A posterior confirmação, em humanos, da resposta cruzada à vacinação de febre amarela com ação protetiva corroborará a necessidade de manutenção da cobertura vacinal, para minimizar os efeitos do ZIKV e outras arboviroses, especialmente nas gestantes em situação de vulnerabilidade.

No caso do Brasil, estratégias reconhecidamente efetivas, como o saneamento básico, condições de moradia e urbanização, têm sido secundarizadas. Ações dessa natureza ultrapassam o setor saúde e demandam esforço intersetorial, sendo fundamentais não apenas para o controle de vetores, mas para redução de iniquidades e vulnerabilidades.

A epidemia do ZIKV evidenciou que, para além das áreas que devem ser priorizadas em uma resposta à emergência sanitária, uma problemática central refere-se às diferentes perspectivas quanto ao direito à saúde, que podem representar ampliação ou restrição de acesso aos serviços e abrangência dos sistemas de saúde, bem como determinar a forma como o sistema responde às demandas. Direitos amplos e universais de saúde aos cidadãos não estão garantidos em todos os países, nem igualmente para toda a população de cada país. Entretanto, para o enfrentamento de futuras emergências relacionadas com arboviroses, uma abordagem integrada deve estar pautada em uma perspectiva abrangente de direito à saúde e equidade.

\section{Agradecimentos}

Os autores agradecem aos integrantes e coordenadores do Projeto 'Ciências Sociais e Humanidades frente à Epidemia de Zika Vírus no Brasil', no qual as pesquisas que originaram este ensaio se inseriram.

\section{Colaboradores}

Pepe VLE (0000-0003-0606-1544)*, Albuquerque MV (0000-0002-0763-6357)*, Osorio-de-Castro CGS (0000-0003-4875-7216)*, Pereira CCA (0000-0003-1389-9214)*, Dias HS (0000-0003-3419-2496)* e Miranda ES (00000002-6204-5023)* contribuíram para a concepção do artigo, elaboração do rascunho, revisão crítica do conteúdo e aprovação da versão final do manuscrito. Oliveira CVS (0000-0002-04641476)*, Reis LGC (0000-0001-5020-2469)* e Reis CB (0000-0002-6118-2130)* contribuíram para a concepção do artigo, elaboração do rascunho e aprovação da versão final do manuscrito.
*Orcid (Open Researcher and Contributor ID). 


\section{Referências}

1. Lima-Camara TN. Emerging arboviruses and public health challenges in Brazil. Rev Saúde Pública. 2016; 50(36):1-7.

2. Lopes N, Nazawa C, Linhares REC. Características gerais e epidemiologia dos arbovírus emergentes no Brasil. Rev Pan-Amaz Saude. 2014; 5(3):55-64.

3. Teixeira MG, Costa MCN, Oliveira WK, et al. The Epidemic of Zika Virus-Related Microcephaly in Brazil: Detection, Control, Etiology, and Future Scenarios. Am J Public Health. 2016; 106(4):601-5.

4. Brasil. Ministério da Saúde. Portaria $n^{\circ} 1.813$, de 11 de novembro de 2015. Declara Emergência em Saúde Pública de Importância Nacional (ESPIN) por alteração do padrão de ocorrência de microcefalias no Brasil. Diário Oficial da União. 12 Abr 2015.

5. World Health Organization. Emergency response framework. 2. ed. Geneva: WHO; 2017.

6. Gulland A. Zika virus is a global public health emergency, declares WHO. BMJ. 2016; (352):i657-i657.

7. Nunes J, Nacif Pimenta D. A epidemia de Zika e os limites da Saúde Global. Lua Nova. 2016; (98).

8. Brasil. Decreto $n^{\circ} 7.616$, de 17 de novembro de 2011. Dispõe sobre a declaração de Emergência em Saúde Pública de Importância Nacional - ESPIN e institui a Força Nacional do Sistema Único de Saúde - FN-SUS. 2011. Diário Oficial da União. 18 Nov 2011.

9. Cutter SL, Boruff BJ, Shirley WL. Social Vulnerability to Environmental Hazards. Soc Sci Q. 2003; 84(2):242-61.

10. Sheikhbardsiri H, Yarmohammadian MH, Rezaei F, et al. Rehabilitation of vulnerable groups in emergencies and disasters: A systematic review. World J Emerg Med. 2017; 8(4):253-63.

11. Fordham M, Lovekamp WE, Thomas DSK, et al. Un- derstanding Social Vulnerability. In: Thomas DSK, Phillips BD, Lovekamp WE, et al., editores. Social Vulnerability to Disasters 2. ed. Boca Raton: CRC Press; 2013.

12. Possas C, Brasil P, Marzochi MC, et al. Zika puzzle in Brazil: peculiar conditions of viral introduction and dissemination - A Review. Mem Inst Oswaldo Cruz. 2017; 112(5):319-27.

13. Brasil. Ministério da Saúde. Boletim Epidemiológico - Sífilis. 2015; 4(1):1-32.

14. Brasil. Ministério da Saúde. Sarampo - Situação Epidemiológica/Dados [internet]. [acesso em 2019 mar 3]. Disponível em: http://www.saude.gov.br/saude-de-a-z/sarampo/situacao-epidemiologica-dados.

15. Brasil. Ministério da Saúde. Boletim Epidemiológico. Monitoramento dos casos de dengue até a semana epidemiológica (SE) 38 e febre de chikungunya até a SE 39 de 2014. 2015; 45(23):1-6.

16. Ferguson NM, Cucunubá ZM, Dorigatti I, et al. EPIDEMIOLOGY. Countering the Zika epidemic in Latin America. Science. 2016; 353(6297):353-4

17. Osorio-de-Castro CGS, Miranda ES, Freitas CM, et al. The Zika Virus Outbreak in Brazil: Knowledge Gaps and Challenges for Risk Reduction. Am J Public Health. 2017; 107(6):960-5.

18. Albuquerque MFPM, Souza WV, Araújo TVB, et al. Epidemia de microcefalia e vírus Zika: a construção do conhecimento em epidemiologia. Cad. Saúde Pública. 2018; 34(10):e00069018

19. Rego S, Palácios M. Ethics, global health and Zika virus infection: a view from Brazil. Rev Bioét. 2016; 24(3):430-4.

20. Haire B. Aspects of disaster research ethics applicable to other contexts. J Med Ethics. 2018; 44(1):9. 
21. Santos BMC, Coelho FC, Armstrong M, et al. Zika: an ongoing threat to women and infants. Cad. Saúde Pública. 2018; 34(11).

22. Rasmussen SA, Jamieson DJ, Honein MA, et al. Zika Virus and Birth Defects - Reviewing the Evidence for Causality. N Engl J Med. 2016; 374(20):1981-7.

23. Brasil. Ministério da Saúde. Ministério da Saúde confirma relação entre vírus Zika e microcefalia. 2015.

24. Essue B, Laba T, Knaul F, et al. Economic Burden of Chronic Ill Health and Injuries for Households in Low - and Middle-Income Countries. In: Jamison DT, Gelband H, Jha PK, et al. Disease Control Priorities: Improving Health and Reducing Poverty. 3. ed. Washington (DC): The World Bank; 2017.

25. Kankeu HT, Saksena P, Xu K, et al. The financial burden from non-communicable diseases in low- and middle-income countries: a literature review. Health Res Policy Syst. 2013; 11(31):1-8.

26. McIntyre D, Thiede M, Dahlgren G, et al. What are the economic consequences for households of illness and of paying for health care in low- and middle-income country contexts? Soc Sci Med. 2006; 62(4):858-65.

27. World Health Organization. WHO guide to identifying the economic consequences of disease and injury. Geneva: WHO; 2009.

28. Oliveira SJGS, Melo ES, Reinheimer DM, et al. Anxiety, depression, and quality of life in mothers of newborns with microcephaly and presumed congenital Zika virus infection. Arch Womens Ment Health. 2016; 19(6):1149-51.

29. Knaul FM. Household spending and impoverishment. Cambridge: Harvard University Press; 2012.

30. Organisation for Economic Co-operation and Development. Sickness, disability and work: breaking the barriers ; a synthesis of findings across OECD countries. Paris: OECD; 2010.
31. Brasil. Presidência da República. Lei no 8.069, de 13 de julho de 1990. Dispõe sobre o Estatuto da Criança e do Adolescente e dá outras providências. Diário Oficial da União. 14 Jul 1990.

32. Fundo das Nações Unidas para a Infância. Children with disabilities. New York: UNICEF; 2013.

33. Organisation for Economic Co-operation and Development. Equity and Quality in Education: Supporting Disadvantaged Students and Schools. Paris: OECD; 2012.

34. Drummond M. Methods for the economic evaluation of health care programmes. 4. ed. Oxford; New York: Oxford University Press; 2015.

35. Syed ST, Gerber BS, Sharp LK. Traveling Towards Disease: Transportation Barriers to Health Care Access. J Community Health. 2013; 38(5):976-93.

36. Bredenkamp C, Mendola M, Gragnolati M. Catastrophic and impoverishing effects of health expenditure: new evidence from the Western Balkans. Health Policy Plan. 2011; 26(4):349-56.

37. Programa das Nações Unidas para o Desenvolvimento. Uma avaliação do impacto socioeconômico do vírus Zika na América Latina e Caribe: Brasil, Colômbia e Suriname como estudos de caso. Nova York: PNDU; 2017.

38. Counotte M, Egli-Gany D, Riesen M, et al. Zika virus infection as a cause of congenital brain abnormalities and Guillain-Barré syndrome: From systematic review to living systematic review. F1000Research. 2018; 7(196):1-20.

39. Garcia LP. Epidemia do vírus Zika e microcefalia no Brasil: emergência, evolução e enfrentamento - Texto para Discussão. Brasília, DF: IPEA; 2018.

40. Garcia LP, Duarte E. Evidências da vigilância epidemiológica para o avanço do conhecimento sobre a epidemia do vírus Zika. Epidemiol Serv Saúde. 2016; 25(4):679-81. 
41. Zara LSA, Santos SM, Fernandes-Oliveira SE, et al. Estratégias de controle do Aedes aegypti: uma revisão. Epidemiol E Serviços Saúde. 2016; 25(2):1-2.

42. Wilder-Smith A, Gubler DJ, Weaver SC, et al. Epidemic arboviral diseases: priorities for research and public health. Lancet Infect Dis. 2017; 17(3):e101-6.

43. Spedo SM, Pinto NRS, Tanaka OY. O difícil acesso a serviços de média complexidade do SUS: o caso da cidade de São Paulo, Brasil. Physis. 2010; 20(3):95372 .

44. Reis LGC. Comentário sobre o artigo de Eickmann. Cad. Saúde Pública. 2016; 32(7):eC0010716.

45. Barreto ML, Barral-Netto M, Stabeli R, et al. Zika virus and microcephaly in Brazil: a scientific agenda. Lancet. 2016; 387(10022):919-21.

46. Vanni T, Chalegre KD, Giaretta Sachetti C, et al. Zika virus emergency in Brazil: scientific challenges and early developments. F1000Research. 2016; (5):1915.

47. Santos ACV, Guedes-da-Silva FH, Dumard CH, et al. Yellow Fever Vaccine Protects Resistant and Susceptible Mice Against Zika Virus Infection. BioRxi. 2019; 1-32.

48. Chen Q, Wu J, Ye Q, et al. Treatment of Human Glioblastoma with a Live Attenuated Zika Virus Vaccine Candidate. mBio. 2018; 9(5):e01683-18.

49. Lowe R, Barcellos C, Brasil P, et al. The Zika Virus Epidemic in Brazil: From Discovery to Future Implications. Int J Environ Res Public Health. 2018; 15(1):96

50. Tavares M, Silva MRM, Oliveira de Siqueira LB, et al. Trends in insect repellent formulations: A review. Int J Pharm. 2018; 539(1-2):190-209.

51. Bowman NM, Akialis K, Cave G, et al. Pyrethroid insecticides maintain repellent effect on knock-down resistant populations of Aedes aegypti mosquitoes. PLoS One. 2018; 13(5):e0196410
52. Mesci P, Macia A, Moore SM, et al. Blocking Zika virus vertical transmission. Sci Rep. 2018; 8(1):1218.

53. Snyder B, Goebel S, Koide F, et al. Synergistic antiviral activity of Sofosbuvir and type-I interferons ( \&\#945; and ß) against Zika virus. J Med Virol. 2018; 90(1):812 .

54. Li Z, Sakamuru S, Huang R, et al. Erythrosin B is a potent and broad-spectrum orthosteric inhibitor of the flavivirus NS2B-NS3 protease. Antivir Res. 2018; (150):217-25.

55. Shiryaev SA, Mesci P, Pinto A, et al. Repurposing of the anti-malaria drug chloroquine for Zika Virus treatment and prophylaxis. Sci Rep. 2017; 7(1):15771.

56. Moreira TMM, Pinheiro JAM, Florencio RS, et al., organizadores. Tecnologias para a promoção e o cuidado em saúde. Fortaleza: EdUECE; 2018.

57. Ventura DFL. Do Ebola ao Zika: as emergências internacionais e a securitização da saúde global. Cad. Saúde Pública. 2016; 32(4): e00033316.

58. World Health Organization. Zika Strategic Response Framework \& Joint Operations Plan. January-June 2016. Genova: WHO; 2016.

59. Wenham C, Farias DB. Securitizing Zika: The case of Brazil. Secur Dialogue. 2019; 50(5):398-415

60. Brasil. Ministério da Saúde. Vírus Zika no Brasil. A resposta do SUS. Brasília, DF: MS; 2017.

61. D’Agostino M, Samuel NO, Sarol MJ, et al. Open data and public health. Rev Panam Salud Pública. 2018; (42):1-8.

62. Pavão ALB, Barcellos C, Pedroso M, et al. The role of Brazilian National Health Information Systems in assessing the impact of Zika virus outbreak. Rev Soc Bras Med Trop. 2017; 50(4):450-7.

63. Ndeffo-Mbah ML, Parpia AS, Galvani AP. Mitigating Prenatal Zika Virus Infection in the Americas. Ann Intern Med. 2016; 165(8):551. 
64. Kroelinger CD, Romero L, Lathrop E, et al. Meeting Summary: State and Local Implementation Strategies for Increasing Access to Contraception During Zika Preparedness and Response - United States, September 2016. Morb Mortal Wkly Rep. 2017; 66(44):12305.

65. Lathrop E, Romero L, Hurst S, et al. The Zika Contraception Access Network: a feasibility programme to increase access to contraception in Puerto Rico during the 2016-17 Zika virus outbreak. Lancet Public Health. 2018; 3(2):e91-9.

66. Ali M, Miller K, Gómez Ponce de Leon RF. Family planning and Zika virus: need for renewed and cohesive efforts to ensure availability of intrauterine contraception in Latin America and the Caribbean. Eur J Contracept Reprod Health Care. 2017; 22(2):102-6.

67. González Vélez AC, Diniz SG. Inequality. Zika epidemics, and the lack of reproductive rights in Latin America. Reprod Health Matters. 2016; 24(48):57-61.

68. Baum P, Fiastro A, Kunselman S, et al. Ensuring a rights-based health sector response to women affected by Zika. Cad. Saúde Pública. 2016; 32(5): e00064416.

69. Lesser J, Kitron U. A geografia social do Zika no Brasil. Estud Avancados. 2016; 30(88):167-75.

70. Valente PK. Zika and Reproductive Rights in Brazil: Challenge to the Right to Health. Am J Public Health. 2017; 107(9):1376-80.

71. Tavares MP, Foster AM. Emergency contraception in a public health emergency: exploring pharmacy availability in Brazil. Contraception. 2016; 94(2):109-14.

72. Ravi SJ. Strengthening Health Systems Through International Blood Product Sharing Agreements. Health Secur. 2017; 15(1):110-7.

73. Bloch EM, Ness PM, Tobian AAR, et al. Revisiting Blood Safety Practices Given Emerging Data about Zika Virus. N Engl J Med. 2018; 378(19):1837-41.
74. Moreira MCN, Nascimento M, Mendes CHF, et al. Emergency and permanence of the Zika virus epidemic: an agenda connecting research and policy. Cad. Saúde Pública. 2018; 34(8): e00075718.

75. Einspieler C, Utsch F, Brasil P, et al. Association of Infants Exposed to Prenatal Zika Virus Infection With Their Clinical, Neurologic, and Developmental Status Evaluated via the General Movement Assessment Tool. JAMA Netw Open. 2019; 2(1):e187235.

76. Sá FE, Andrade MMG, Nogueira EMC, et al. Produção de sentidos parentais no cuidado de crianças com microcefalia por vírus zika. Rev Bras Em Promoção Saúde. 2017; 30(4):1-10.

77. Diniz D. Vírus Zika e mulheres. Cad. Saúde Pública. 2016; 32(5): e00046316.

78. Brasil. Ministério da Saúde, Fundação Oswaldo Cruz, Instituto Fernandes Figueira. Guia prático de direitos para profissionais de saúde e famílias de crianças com a síndrome congênita do Zika vírus no Rio de Janeiro. Rio de Janeiro: MS; Fiocruz; IFF; 2019.

79. Freire IM, Pone SM, Ribeiro MC, et al. Síndrome congênita do Zika vírus em lactentes: repercussões na promoção da saúde mental das famílias. Cad. Saúde Pública. 2018; 34(9):e00176217.

80. Brunoni D, Blascovi-Assis SM, Osório AAC, et al. Microcephaly and other Zika virus related events: The impact on children, families and health teams. Ciênc. Saúde Colet. 2016; 21(10):3297-302.

81. Morain SR, Wootton SH, Eppes C. A Devastating Delay - Zika and the Implementation Gap. N Engl J Med. 2017; 377(16):1505-7.

Recebido em 10/07/2019

Aprovado em 18/02/2020

Conflito de interesses: inexistente

Suporte financeiro: European Union's Horizon 2020 Research and Innovation Programme under ZIKAlliance Grant Agreement no 734548 